УДК 676.054.6

\title{
ПРЯМОЙ МЕТОД КОНТРОЛЯ КАЧЕСТВА ПОВЕРХНОСТИ МЕЛОВАННЫХ ВИДОВ БУМАГИ
}

\author{
() А.А. Кирсанкин ${ }^{1}$, М.Г. Михалева ${ }^{1}$, С.Н. Никольский ${ }^{*}$, А.В. Мусохранова ${ }^{2}$ С.В. Стовбун \\ ${ }^{1}$ Институт химической фризики им. Н.Н. Семенова РАН, ул. Косыгина, 4, \\ Москва, 119991 (Россия), e-mail: nikolskij56@mail.ru \\ ${ }^{2}$ ООО «Европапир», ул. Большая Переяславская, 46/2, Москва, 129110 (Россия)
}

Рассмотрены возможности анализа качества поверхности мелованных видов бумаги с применением атомносиловой микроскопии. Показано, что техника анализа поверхности целлюлозно-бумажных материалов с использованием АСМ является достаточно универсальной и дает объективную характеристику шероховатости различных видов целлюлозно-бумажной продукции. В отличие от традиционных «воздушных» методов контроля качества целлюлознобумажной продукции, которые стандартизированы как в системе ISO, так и в рамках национальных и отраслевых систем по стандартизации (ГОСТ, DIN, SCAN, TAPPI), этот метод дает прямое изображение рельефа поверхности (близкое к 3D). Обработка полученных изображений поверхности листа с применением встроенного программного обеспечения позволяет рассчитать шероховатость в полном соответствии с требованиями ГОСТ 2789-73 и международной рекомендации по стандартизации ИСО Р 468. Следует отметить, что полученные данные согласуются с данными, полученными другими методами, однако в некоторых случаях при равном косвенном показателе шероховатости, указанном производителем, прямой расчет параметра Ra по данным ACM дает разные результаты. Данный метод прямого анализа поверхности мелованных видов бумаги, использованный в работе, может в перспективе рассматриваться как метод оперативного контроля процессов поверхностной обработки различных материалов.

Ключевые слова: шероховатость, гладкость, атомно-силовая микроскопия, мелованная бумага, поверхность.

\section{Введение}

Современные наилучшие доступные технологии в производстве и переработке целлюлознобумажной продукции неразрывно связаны с разработкой и внедрением инновационных методов контроля качества материалов по стадиям процесса и, главное, характеристик конечной продукции.

Сказанное в полной мере относится и к носителям информации на бумажной основе. Интенсивное развитие современных методов печати ведет к постоянному повышению требований к качеству мелованного слоя бумаги и картона.

Одним из наиболее важных показателей качества бумаги является шероховатость. Она обусловливает способность бумаги передавать печатную информацию без искажений и разрывов. Согласно ГОСТ 30115-95, шероховатость - это неровность поверхности, которая определяется по расходу воздуха [1]. Дан-

Кирсанкин Андрей Александрович - доктор физикоматематических наук, научный сотрудник, e-mail: aakirsankin@chph.ras.ru

Михалева Мария Геннадьевна - аспирант, e-mail: wawe@bk.ru

Никольский Сергей Николаевич - кандидат химических наук, старший научный сотрудник, e-mail: nikolskij56@mail.ru

Мусохранова Анна Витальевна - менеджер по развитию мелованных и специальных бумаг, e-mail: a.musohranova@europapier.ru

Стовбун Сергей Витальевич - доктор физикоматематических наук, заведующий лабораторией, e-mail: s.stovbun@chph.ras.ru ное определение не имеет ничего общего с одним из базовых понятий материаловедения, которое распространяется на шероховатость поверхности изделий независимо от их материала и способа изготовления (получения поверхности) [2]. Еще раз подчеркнем, что неровность поверхности не может определяться по расходу воздуха.

В соответствии с ГОСТ 2789-73, шероховатость поверхности - это совокупность неровностей с относительно малыми шагами, образующих рельеф поверхности. Шероховатость поверхности определяется по ее профилю, который представляет со-

\footnotetext{
* Автор, с которым следует вести переписку.
} 
бой ломаную линию пересечения поверхности плоскостью, перпендикулярной направлению неровностей. Профиль рассматривается на длине базовой линии, в пределах которой оцениваются параметры шероховатости поверхности $[2,3]$.

В настоящей работе изучение топографии поверхности бумаги и картона для полиграфии проведено с применением метода атомно-силовой микроскопии (АСM). Показано, что техника анализа поверхности целлюлозно-бумажных материалов с использованием АСМ является достаточно универсальной и дает объективную характеристику шероховатости очень широкого спектра различных видов целлюлознобумажной продукции - от товарной целлюлозы до бумаги с глянцевым мелованным слоем.

\section{Экспериментальная часть}

Все измерения методом атомно-силовой микроскопии (АСM) были выполнены на микроскопе Solver HV (ЗАО NT-MDT, Зеленоград, Россия), работающем в полуконтактном режиме, при комнатной температуре и атмосферном давлении.

Образец бумаги помещали на поверхность стандартной кремниевой пластины, используемой в микроэлектронной промышленности. Далее подготовленный образец устанавливали в АСМ. Кондиционирование образцов бумаги не проводили.

Измерения рельефа поверхности образца в АСМ проводили в области значений размеров поля зре-

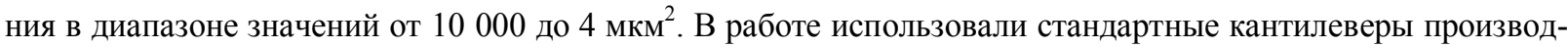
ства ЗАO NT-MDT (Зеленоград, Россия). Собственные частоты кантилеверов находились в диапазоне 110 180 кГц, радиус закругления зонда - 10 нм. На топографических изображениях, полученных в режиме постоянной амплитуды, высота профиля передается цветом: чем выше находится деталь рельефа, тем она светлее.

Принцип работы атомно-силового микроскопа заключается в регистрации силового взаимодействия между кантилевером и поверхностью образца. При взаимодействии кантилевера с поверхностью на него действует сила, которая приводит к изгибу его основания. Различия в высотах на поверхности исследуемого образца при этом отражаются в изменении силы, действующей на кантилевер, и, следовательно, приводят к изменению изгиба его основания. Величина изгиба регистрируется при помощи лазера, направленного на основание кантилевера, и по ней можно судить о рельефе поверхности.

\section{Обсуждение результатов}

В настоящее время в целлюлозно-бумажном производстве наиболее распространенными и повсеместно применяемыми методами количественной оценки качества поверхности бумаги и картона для полиграфии являются: гладкость по Бекку [4]; шероховатость по Бендтсену [5]; шероховатость по Паркеру PPS [6].

Сущность данных методов заключается в измерении скорости протекания воздуха между поверхностью бумаги и анализатором, форма и характеристики которого зависят от метода определения. Независимо от принципа измерения все методы обладают одним общим свойством - они косвенные и дают усредненную (брутто) характеристику состояния поверхности запечатываемого материала. При этом метод Паркера, который в результате дает среднее значение профиля поверхности в микрометрах, на самом деле является расчетным и его результат пересчитывается в любые единицы измерения [7]. Следовательно, очень высока вероятность получения идентичных результатов контрольных анализов конечной продукции при различных реальных состояниях поверхности тестируемого материала.

В работе рассматривается использование прямого метода количественного анализа качества мелованного покрытия. В отличие от традиционных для анализа целлюлозных материалов методов микроскопического анализа (оптическая микроскопия, сканирующая электронная микроскопия) использована атомно-силовая микроскопия. Этот раздел современной микроскопии стал применяться для исследования материалов на целлюлозной основе лишь в последнее время (см., например, [8-11]).

При обработке данных АСМ рассматривали выделенный профиль, проводимый через наивысшую и наинизшую точку исследуемой поверхности. Длина отрезка прямой, на котором оценивается профиль поверхности, превышает длину базовой линии, предусмотренной в соответствующих нормативных документах [2]. Программное обеспечение прибора АСМ позволяет рассчитать параметры шероховатости поверхности в точном соответствии с ГОСТ 2789-73 [2]. 
В экспериментах использованы образцы мелованных видов бумаги, серийно выпускаемых ведущими предприятиями РФ, Западной Европы и Азии: группа «Илим», SUN PAPER, STORAENSO, UPM.

Представленные ниже результаты сканирования поверхности мелованных образцов бумаги наглядно демонстрируют преимущества и достоинства метода АСМ для контроля качества целлюлознобумажной продукции для полиграфии (рис. 1, 2, табл). Важно отметить, что полученные нами данные удовлетворительно согласуются с показателями шероховатости по методу Паркера (табл.), однако в некоторых случаях, при одинаковом косвенном показателе шероховатости, указанном производителем, прямой расчет параметра Ra из данных ACM дает разные результаты, что говорит о большей точности метода ACM. Отметим, что по данным полиграфистов результаты, полученные при помощи АСМ, более объективно отражают качество бумаги для печати. Из соображений конфиденциальности информация конкретных изготовителей и марок продукции не указана.

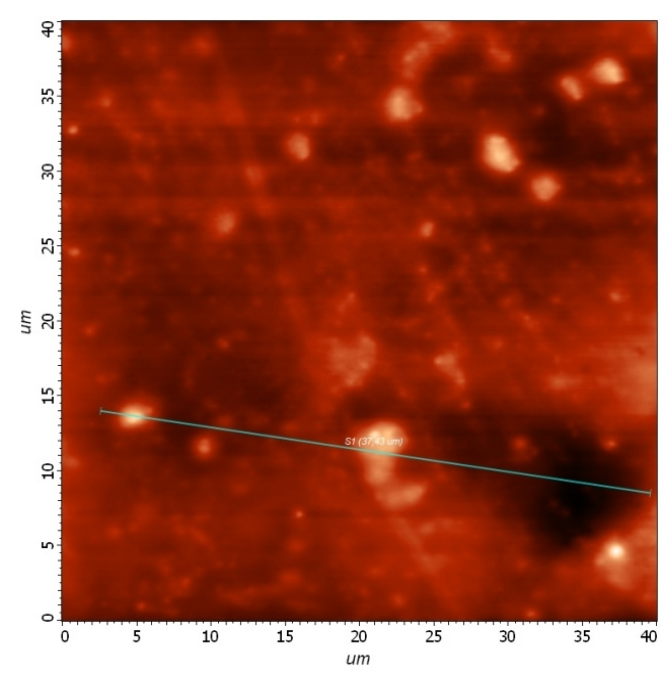

A

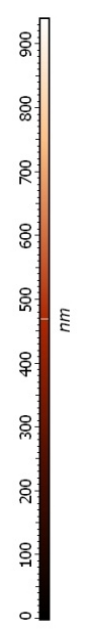

Рис. 1. А - топографическое АСМ изображение поверхности мелованной бумаги образца 1; Б - профиль выделенной линии поверхности, проведенной через наивысшую и наинизшую точку рассматриваемой области

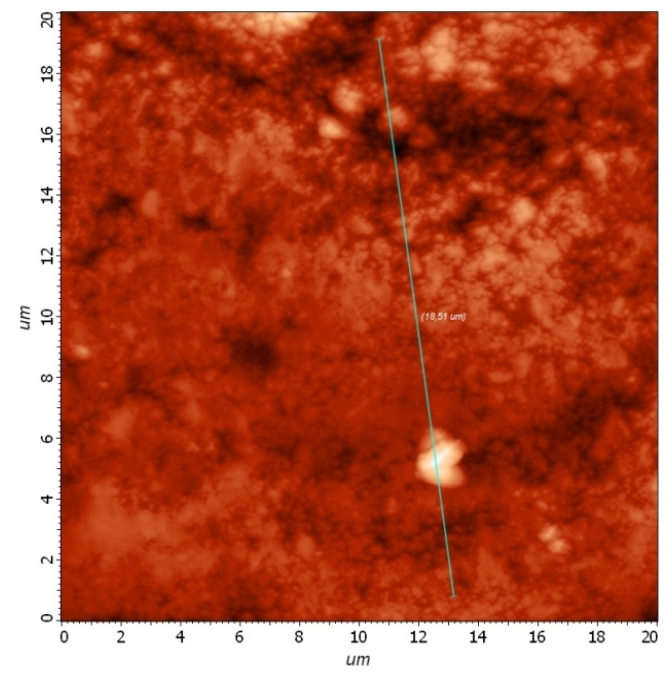

A

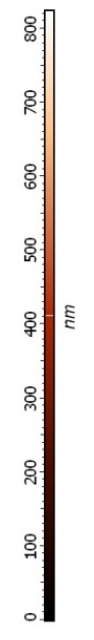

Б

Рис. 2. А - топографическое АСМ изображение поверхности мелованной бумаги образца 2; Б - профиль выделенной линии поверхности, проведенной через наивысшую и наинизшую точку рассматриваемой области 
Сравнение шероховатости образцов по методу Паркера и по данным АCM

\begin{tabular}{c|c|c|c}
\hline \multirow{2}{*}{$№$ образца } & $\begin{array}{c}\text { Масса } \\
1 \mathrm{~m}^{2}, \Gamma\end{array}$ & $\begin{array}{c}\text { Шероховатость по методу Паркера } \\
\text { PPS } 10(\mu \mathrm{m})\end{array}$ & $\begin{array}{c}\text { Шероховатость по АСМ } \\
\text { Ra, нм }\end{array}$ \\
\hline 1 & 115 & 1,0 & 104 \\
2 & 115 & 0,7 & 67 \\
3 & 115 & 0,7 & 99 \\
\hline
\end{tabular}

В заключение укажем, что метод прямого анализа поверхности мелованных видов бумаги, использованный в работе, может в перспективе рассматриваться как метод оперативного контроля процессов поверхностной обработки различных материалов.

К преимуществам метода относятся:

- небольшая продолжительность анализа. Экспресс-контроль выполняется в течение 20-30 мин. Полный анализ с измерениями и обработкой массива данных - в течение 50-60 мин.

- кондиционирование образцов не требуется.

- приемлемая цена оборудования, выпускаемого российскими предприятиями. В ценах настоящего времени стоимость прибора в зависимости от марки и выполняемых функций сопоставима со стоимостью аналитических весов I класса точности.

Работы в данном направлении продолжаются.

Авторы выражают благодарность генеральному директору ООО «РТА - Санкт-Петербург» Кузиной Марине Николаевне за предоставленную информацию по прибору Паркера (PPS).

\section{Список литературы}

1. ГОСТ 30115-95 (ИСО 8791-1) Бумага и картон. Определение шероховатости/гладкости (методы с применением пропускания воздуха). Общие требования. М., 1999. 7 с.

2. ГОСТ 2789-73 (Рекомендация ИСО Р 486) Шероховатость поверхности. Параметры и характеристики. М., 2006. $7 \mathrm{c}$.

3. МИ 41-75 Методика выполнения измерений параметров шероховатости поверхности по ГОСТ 2789-73 при помощи приборов профильного метода. М., 1975. 18 с.

4. ГОСТ 12795-89 (ИСО 5627) Бумага и картон. Метод определения гладкости по Бекку. М., 1989. 7 с.

5. ГОСТ 30022.2-93 (ИСО8791-2-90) Бумага и картон. Метод определения шероховатости (метод с применением пропускания воздуха). Метод Бендтсена. М., 1993. 17 с.

6. DIN ISO 8791-4:2008-05 Paper and board - Determination of roughness/smoothness (air leak methods) - Part 4: Print-surf method (ISO 8791-4:2007). 26 p.

7. Компания FRANK-PTI - Мартин Кальтенбруннер. - PTA-Line Print Surf (PPS) Руководство по эксплуатации. 2011. $16 \mathrm{c}$.

8. Вячеславова О.Ф., Бавыкин О.Б. Современные методы оценки качества поверхности деталей машин: учебное пособие. М., 2010. 74 с.

9. Жуков М.В. Контроль структуры различных видов бумаги методом атомно-силовой микроскопии // Научнотехнический вестник информационных технологий, механики и оптики. 2014. №1. С. 44-49.

10. Jandira Maria de O.B. Brandão Documentoscopy by atomic force microscopy (AFM) coupled with Raman microspectroscopy: applications in banknote and driver license analyses // Anal. Methods. 2016. Pp. 771-784.

11. Антоненко С.В. Создание композиционной графитовой бумаги с нанотрубками и изучение ее свойств с помощью СЗМ и ПЭМ // Научная сессия МИФИ. 2010. Т.3. С. 34-35.

Поступило в редакиию 13 июля 2016 г. 
Kirsankin A.A. ${ }^{l}$, Mikhaleva M.G. ${ }^{l}$, Nikolskii S.N. ${ }^{1 *}$, Musohranova A.V. ${ }^{2}$, Stovbun S.V. ${ }^{l}$ DIRECT METHOD OF QUALITY CONTROL SURFACE COATED TYPES OF PAPER

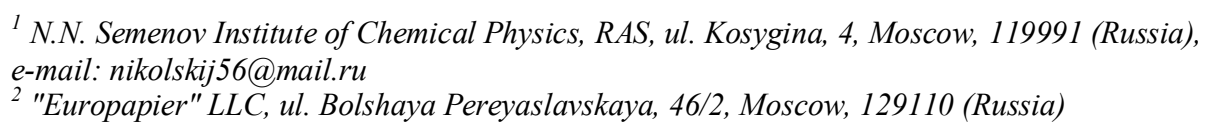

The possibilities of surface quality analysis of coated paper types using atomic force microscopy are considered. It is shown that the technique of surface analysis of pulp and paper materials using AFM is quite versatile and gives a reliable characterization of roughness of different types of pulp and paper products. In contrast to traditional "air" quality control methods for of paper products, which are standardized in ISO system, and through of national and industry standardization systems (GOST, DIN, SCAN, TAPPI), this method gives a direct image of the surface topography (close to 3D image). Processing of the image surface of the sheet using embedded software allows calculating the roughness in full accordance with the requirements of GOST 2789-73 and the international recommendations for the standardization of ISO P 468. It should be noted that the obtained data are consistent with those obtained by other methods, however, in some cases, equal to indirect measure of roughness specified by the manufacturer, the direct calculation of the Ra parameter according to the AFM gives different results. This method of direct surface analysis of coated papers used in the work, can in future be considered as a method of operative control processes for the surface treatment of various materials.

Keywords: roughness, smoothness, atomic force microscopy, coated paper, and the surface.

\section{References}

1. GOST 30115-95 (ISO 8791-1) Bumaga i karton. Opredelenie sherokhovatosti/gladkosti (metody s primeneni-em propuskaniia vozdukha). Obshchie trebovaniia. [GOST 30115-95 (ISO 8791-1) Paper and paperboard. Determination of roughness / smoothness (methods using air transmission). General requirements]. Moscow, 1999, 7 p. (in Russ.).

2. GOST 2789-73 (Rekomendatsiia ISO R 486) Sherokhovatost' poverkhnosti. Parametry i kharakteristiki. [GOST 278973 (Recommendation ISO R 486) surface roughness. Parameters and characteristics]. Moscow, 2006, 7 p. (in Russ.).

3. MI 41-75 Metodika vypolnenia izmerenii parametrov sherokhovatosti poverkhnosti po GOST 2789-73 pri pomoshchi priborov profil'nogo metoda. [MI 41-75 method for measuring surface roughness parameters according to GOST 2789-73 method of using profile devices]. Moscow, 1975, 18 p. (in Russ.).

4. GOST 12795-89 (ISO 5627) Bumaga i karton. Metod opredeleniia gladkosti po Bekku. [GOST 12795-89 (ISO 5627) Paper and paperboard. Method for determination of smoothness Becca]. Moscow, 1989, 7 p. (in Russ.).

5. GOST 30022.2-93 (ISO8791-2-90) Bumaga i karton. Metod opredeleniia sherokhovatosti (metod s primeneniem propuskaniia vozdukha). Metod Bendtsena. [GOST 30022.2-93 (ISO8791-2-90) Paper and paperboard. determination of roughness method (method using air transmission). Bendtsen method]. Moscow, 1993, 17 p. (in Russ.).

6. DIN ISO 8791-4:2008-05 Paper and board - Determination of roughness/smoothness (air leak methods) - Part 4: Print-surf method (ISO 8791-4:2007). 26 p.

7. Kompaniia FRANK-PTI - Martin Kal'tenbrunner. - PTA-Line Print Surf (PPS) Rukovodstvo po ekspluatatsii. [The company FRANK-PTI - Martin Kaltenbrunner. - PTA-Line Print Surf (PPS) Operating Instructions]. 2011, 16 p. (in Russ.).

8. Viacheslavova O.F., Bavykin O.B. Sovremennye metody otsenki kachestva poverkhnosti detalei mashin: uchebnoe posobie. [Modern methods of assessing the quality of machine parts surface: a tutorial]. Moscow, 2010, 74 p. (in Russ.).

9. Zhukov M.V. Nauchno-tekhnicheskii vestnik informatsionnykh tekhnologii, mekhaniki i optiki, 2014, no. 1, pp. 44-49. (in Russ.).

10. Jandira Maria de O.B. Brandão. Anal. Methods, 2016, pp. 771-784.

11. Antonenko S.V. Nauchnaia sessiia MIFI, 2010, vol. 3, pp. 34-35. (in Russ.). 
